\title{
Compared effects of three oligosaccharides on metabolism of intestinal microflora in rats inoculated with a human faecal flora
}

\author{
BY ZAKIA DJOUZI AND CLAUDE ANDRIEUX* \\ Laboratoire d'Ecologie et de Physiologie du Système Digestif, Bât. 440, INRA-CRJ, \\ 78352 Jouy en Josas Cedex, France
}

(Received 4 March 1996-Revised 13 December 1996-Accepted 16 December 1996)

\begin{abstract}
Using germ-free rats inoculated with a human faecal flora (gnotobiotic rats), the effects of three oligosaccharides ( $\beta$-fructo-oligosaccharides (FOS), $\beta$-galacto-oligosaccharides (TOS) and $\alpha$-glucooligosaccharides (GOS)) on intestinal bacterial metabolism were compared. The animals were fed on either a control diet or diets containing $40 \mathrm{~g} / \mathrm{kg}$ of GOS, FOS or TOS. FOS and TOS were the preferred growth substrates for Bifidobacteria which increased in number by 2 log values in faeces of rats when compared with rats fed on GOS or control diets. Ingestion of TOS specifically induced hydrolysis of the substrate, and did not modify the activity of any other enzymes measured in the caecum. GOS led to a non-specific enzymic induction of $\beta$-galactosidase $(E C$ 3.2.1.23), $\beta$-glucosidase $(E C$ 3.2.1.21) and $\alpha$-glucosidase $(E C$ 3.2.1.20) activities whereas $\beta$-glucuronidase $(E C$ 3.2.1.31) was lowered. Compared with the control group, $\mathrm{FOS}$ and TOS diets led to a significant increase in $\mathrm{H}_{2}$ and $\mathrm{CH}_{4}$ excretion; the GOS diet increased only $\mathrm{CH}_{4}$. Analysis of caecal contents revealed a decrease in $\mathrm{pH}$ for all diets compared with controls. Total short-chain fatty acid (SCFA) concentration increased significantly in all groups, but the SCFA profile differed between treatment groups. It was concluded that the three oligosaccharides studied had different effects which may be linked to their chemical structure. Some of these effects may be beneficial to human health.
\end{abstract}

Oligosaccharides: Fermentation: Gnotobiotic rats

The intestinal microflora plays a considerable role in the metabolism of endogenous and exogenous substances in the diet, and is thought to participate in beneficial and deleterious effects on human health. Several attempts to improve bacterial metabolism in a beneficial way have been made. One strategy is to supplement the diet with substances that promote the growth of lactic acid bacteria which are thought to be important for health. These bacteria are recognized to create conditions unfavourable for the growth of potentially pathogenic species (Mutai \& Tanaka, 1987) and they can produce B vitamins and lysozyme (Tamura, 1983). Moreover, as dietary supplements and as starter cultures in fermented milks, they are thought to help prevent constipation and regulate transit time (Hitchins \& McDonough, 1989), to prevent diarrhoea (Saavedra et al. 1994) and to treat antibioticassociated diarrhoea (Mitsuoka, 1982), to prevent colonic cancer (Goldin \& Gorback, 1984; Marteau et al. 1990), to be immunomodulators (Fernandes \& Shahani, 1990; De Simone et al. 1993; Schiffrin et al. 1995) and to reduce blood lipid levels (Gilliland, 1990). In human subjects, fructo- and galacto-oligosaccharides are known for their ability to stimulate the growth of Bifidobacterium and Lactobacillus and to inhibit that of potentially pathogenic bacteria, Enterobacteria, Clostridium and Salmonella (Tanaka et al. 1983; Mitsuoka et al. 1987; Ito et al. 1990). These sugars have been shown to be resistant to 
endogenous glycolytic enzymes and to pass unaltered to the hindgut where they are totally fermented by the microflora which leads to the reduction of bacterial activities responsible for the generation of toxic and carcinogenic products (Ito et al. 1993).

Carbohydrate fermentation leads to the production of metabolites, short-chain fatty acids (SCFA), lactic acids and gases in proportions depending upon the chemical structure of the carbohydrates and the bacteria involved (Macfarlane \& Cummings, 1991). Among these metabolites, butyrate is known to be the major substrate for energy metabolism in colonic mucosa and it stimulates epithelial cell growth (Roediger, 1980, 1982). The other SCFA and lactic acids are rapidly absorbed and represent potential substrates for the liver and various tissues (Bergman, 1990). Gases, on the contrary, are excreted without being used by the host and cause flatus discomfort (Grimble, 1989). It is therefore important for human health and intestinal comfort to know the major metabolites produced during the fermentation of oligosaccharides.

In human subjects, in vivo study is complicated by variations between individuals. Since the human flora inoculated in gnotobiotic rats retains the major characteristics of the flora in terms of bacterial population, enzyme activities and metabolite profile, such rats provide a good model for in vivo study of the human gut microflora (Mallet et al. 1987; Debure et al. 1989; Andrieux et al. 1991; Rumney \& Rowland, 1992). The properties of $\beta$ galacto-oligosaccharides (TOS) have already been studied in this animal model (Kikuchi et al. 1992; Rowland \& Tanaka, 1993); those of $\beta$-fructo-oligosaccharides (FOS) and $\alpha$ gluco-oligosaccharides (GOS) are less well known. We showed previously that tri- to hepta-gluco-oligosaccharides were resistant to the action of enzymic hydrolysis in the gastrointestinal tract (Djouzi et al. 1995) and were totally fermented in gnotobiotic rats inoculated with a human microflora (Valette et al. 1993).

The aim of the present study was to compare the effect of three oligosaccharides with different structures (FOS, TOS and GOS) on the composition and the metabolism of a human microflora obtained from a $\mathrm{CH}_{4}$ producer, using gnotobiotic rats as a model. Age and ethnic factors influence $\mathrm{CH}_{4}$ production and it is known that $50 \%$ of the adult Western population produces measurable amounts of $\mathrm{CH}_{4}$ (Bond et al. 1971). The beneficial sideeffects of $\mathrm{CH}_{4}$-producing flora $v$. non- $\mathrm{CH}_{4}$-producing flora have not reached consensus, since $\mathrm{CH}_{4}$ was frequently found in the breath of subjects suffering colonic cancer but it was also found in populations presenting a low risk of cancer (Segal et al. 1988). We previously showed that FOS are able to modify the excreted $\mathrm{H}_{2}: \mathrm{CH}_{4}$ ratio in gnotobiotic rats (Andrieux et al. 1991). Using several approaches, we studied the potential beneficial effects of the three oligosaccharides on health: cholesterolaemia, triacylglycerolaemia, main bacterial genera and bacterial metabolism.

\section{MATERIALS AND METHODS}

\section{Oligosaccharides}

GOS were provided by BioEurope, Toulouse, France and contained $(\mathrm{g} / \mathrm{kg})$ : monosaccharides 10 , disaccharides 90 , tri- to hexasaccharides with $\alpha-1,6$ linkages (glucose- $(1,6)_{n}{ }^{-}$ maltose) 330, and tetra- to heptasaccharides with $\alpha-1,2$ and $\alpha-1,6$ linkages (glucose- $(1,2)$ -

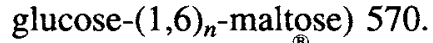

FOS (Raftilose ${ }^{\text {P }}$ P95) were provided by the Raffinerie Tirlemontoise, Tienen, Belgium and contained $(\mathrm{g} / \mathrm{kg})$ : monosaccharides 50 , di- and trisaccharides 270 , tetrasaccharides 310 , penta- to heptasaccharides with $\beta-1,2$ linkages (glucose- $(1,4)$-fructose- $(1,2)_{n}$ and fructose$\left.(1,2)_{n}\right) 340$. 
TOS (grade 100) were provided by the Yakult Institute, Tokyo, Japan, and contained $(\mathrm{g} / \mathrm{kg})$ : mono- and disaccharides 10 , trisaccharides 480 , tetrasaccharides 370 and penta- to hexasaccharides of galactose-(galactose) ${ }_{n}$-glucose, with $\beta-1,6 \beta 1,4$ and $\beta-1,3$ linkages 130 .

\section{Animals and diet}

Twenty-four germ-free ( 2.5 months old) male rats of the Fischer 344 strain were used. The animals were kept in a Trexler-type isolator (Trexler, 1959) fitted with a rapid transfer system (La Cahlène, Vélizy, France) throughout the experiment. They were fed ad libitum for 1 week with a control diet sterilized by irradiation and containing $(\mathrm{g} / \mathrm{kg})$ : mashed potatoes 460 , fish meal 230 , cellulose 50 , maize oil 40 , lard 100 , sucrose 100 , mineral and vitamin mixture 20 . Then the rats were inoculated with $1 \mathrm{ml}$ of a suspension of fresh human faeces; the faecal dilution was performed in an anaerobic Freter's chamber $\left(\mathrm{H}_{2}-\mathrm{CO}_{2}-\mathrm{N}_{2}\right.$ $15: 5: 80$, by vol.). At 2 weeks after inoculation, the rats were divided into four groups of six animals. During a 4-week adaptation period, one group was fed on the control diet, the other three groups received the diet containing $40 \mathrm{~g}$ oligosaccharides $/ \mathrm{kg}$ (GOS, FOS or TOS) which replaced the same amount of sucrose. The foods were sterilized by irradiation at $40 \mathrm{kGy}$ in plastic vacuum bags and distributed ad libitum to the rats.

The rats were then transferred to a respiratory chamber for $4 \mathrm{~d} ; \mathrm{H}_{2}$ and $\mathrm{CH}_{4}$ production values were measured as described by Le $\mathrm{Coz}$ et al. (1989). Bacteria were counted in the faeces samples as described later. Then fed rats were anaesthetized with ether, blood was collected from the abdominal artery in order to obtain samples of plasma which were stored at $-80^{\circ}$ until analysed. The caecum was removed and weighed, the $\mathrm{pH}$ measured and the contents immediately frozen before measuring metabolites and enzymic activity.

\section{Plasma cholesterol and triacylglycerols}

Total cholesterol and triacylglycerol concentrations were measured in plasma samples using commercial enzyme kits (Boehringer-Mannheim, 38242 France).

\section{Bacterial enumeration}

Rat faeces were diluted to $10^{-9}$ in an anaerobic Freter's chamber, in a pre-reduced liquid medium containing (g/l): casein enzymic hydrolysate (USBC, Cleveland, Ohio, USA) 2, yeast extract (Difco, Detroit, MI, USA) 2, $\mathrm{NaCl} 5$ and $\mathrm{KH}_{2} \mathrm{PO}_{4} 1$. Then, the dilutions $10^{7}$, $10^{8}$ and $10^{9}$ were plated $(0.1 \mathrm{ml})$ on the selective agars listed: BHI containing neomycin for Bacteroides, Beerens for Bifidobacterium (Beerens, 1990), 8HPT for Clostridium, GAPTS1 with azide for enterococci, and DCA for enterobacteria. Plates containing BHI or Beerens medium were incubated for $48 \mathrm{~h}$ at $37^{\circ}$ in the anaerobic chamber; those containing GAPTSI and DCA were incubated aerobically. Cultures were made in triplicate. Colonies were counted and bacteria were observed microscopically.

\section{Culture media}

The following agar media were used for analysing the microflora: BHI medium containing (g/l): brain heart infusion (Difco) 37, yeast extract (Difco) 5, haemin 0.005, BHI medium was supplemented with neomycin sulfate $0.2 \mathrm{~g} / \mathrm{l}$ for Bacteroides; Beerens medium containing ( $\mathrm{g} / \mathrm{l}$ ): brain heart infusion (Difco) 37, yeast extract (Difco) 5.0 and cystine chlorhydrate 0.5 , was used for Bifidobacteria. GAPTS1 medium $(\mathrm{pH}, 7.5)$ used for 
Enterococcus contained (g/l): yeast extract (Difco) 10, peptone $15 \cdot 0$, sucrose 1.0 and sodium azide 3.0. The medium used for clostridia numeration $(8 \mathrm{HPT})$ contained $(\mathrm{g} / \mathrm{l})$ : peptone $15 \cdot 0$, tryptone $10 \cdot 0$, liver extracts $5 \cdot 0$, medium $\mathrm{pH}$ was adjusted to 8 . DCA agar medium (for enterobacteria) contained $(\mathrm{g} / \mathrm{l})$ : peptone 10.0, lactose (Sigma, L'Isle d'Abeau Chesnes, France) 10.0, sodium deoxycholate (Sigma) 5.0; $\mathrm{NaCl} 5 \cdot 0, \mathrm{Na}_{2} \mathrm{HPO}_{4} 2 \cdot 0$, iron citrate $1 \cdot 0$, sodium citrate $1 \cdot 0$, neutral red 0.03 . For anaerobes, plates containing the media were kept in the anaerobic chamber for $24 \mathrm{~h}$ before analysis.

\section{Bacterial metabolism studies}

The enzyme assays were performed in the anaerobic chamber in $2 \mathrm{ml}$ Eppendorf tubes. Glycolytic activity was measured by the rate of release of $p$-nitrophenol from $p$ nitrophenylglucosides. The reaction mixture contained $0.3 \mathrm{ml}$ substrate solution $(5 \mathrm{~mol} / \mathrm{l})$ and $0.2 \mathrm{ml}$ of the dilution $1: 2(\mathrm{v} / \mathrm{v})$ of caecal sample in a phosphate buffer $\mathrm{pH} 6.4,0.1$ $\mathrm{mol} /$. Incubation was at $37^{\circ}$ and $p$-nitrophenol concentration was measured according to the optical absorbance at $400 \mathrm{~nm}$ after addition of $2.5 \mathrm{ml}$ M-sodium carbonate. Enzyme activity was expressed as $\mu$ mol product formed per min (IU) per g caecal sample.

$\mathrm{H}_{2}$ and $\mathrm{CH}_{4}$ collected in respiratory chambers were measured using a Quintron apparatus (D-P Quintron Instrument, ABS, France).

SCFA and ethanol were analysed after water extraction of acidified samples, using a GLC (Nelson 1020, Perkin-Elmer, St Quentin en Yvelines, France) equipped with a flameionization detector and a wide-bore column $(15 \mathrm{~m} \times 0.53 \mathrm{~mm})$ (FSCAP Nukol, Supelco, L'Isle d'Abeau Chesnes, France) impregnated with SP 1000. Carrier gas $\left(\mathrm{N}_{2}\right)$ flow-rate was $30 \mathrm{ml} / \mathrm{min}$, column temperature $125^{\circ}$, detector temperature $155^{\circ}, \mathrm{H}_{2}$ and compressed air flow-rate $40 \mathrm{ml} / \mathrm{min}$. 2[Ethyl]butyrate was used as the internal standard.

L- and D-lactate were determined enzymically (Boehringer-Mannheim). $\mathrm{NH}_{3}$ was measured using the Berthelot method adapted by Drospy \& Boy (1965).

\section{Statistical analyses}

Results are expressed as mean values with their standard errors. Data were analysed using ANOVA. Where ANOVA indicated significant treatment effects, means were compared using the Newman-Keuls procedure. Statistical significance was accepted at a probability level of $P<0.05$.

\section{RESULTS}

\section{Plasma cholesterol and triacylglycerol concentrations}

Compared with the control group, the plasma cholesterol concentration was significantly lower $(P<0.05)$ in rats fed with oligosaccharides, whatever the product ingested (Table 1$)$. Plasma triacylglycerol concentrations remained unchanged in all groups.

\section{Bacterial enumeration}

The numbers of Bacteroides, Bifidobacterium, Clostridium, Enterococcus and Enterobacteria were similar in faeces of rats fed on the diet containing GOS and in those fed on the control diet (Table 2). In the latter, Bacteroides were largely dominant compared with 
Table 1. Plasma cholesterol and triacylglycerol concentrations (mmol/) in gnotobiotic rats receiving diets containing $40 \mathrm{~g} / \mathrm{kg}$ of different oligosaccharides for up to 6 weeks $\dagger$

(Mean values with their standard errors for six rats)

\begin{tabular}{llllll}
\hline & \multicolumn{2}{c}{ Cholesterol } & & \multicolumn{2}{c}{ Triacylglycerols } \\
\cline { 2 - 3 } \cline { 5 - 6 } Diet group & Mean & SEM & & Mean & SEM \\
\hline Control & $3 \cdot 10$ & 0.39 & 2.71 & 0.34 \\
GOS & $1.71^{*}$ & 0.13 & 2.26 & 0.16 \\
FOS & $1.96^{*}$ & $0 \cdot 10$ & $3 \cdot 16$ & $0 \cdot 11$ \\
TOS & $2 \cdot 15^{*}$ & 0.05 & 2.36 & 0.11 \\
\hline \hline
\end{tabular}

GOS, diet containing $40 \mathrm{~g}$ gluco-oligosaccharides $/ \mathrm{kg}$; FOS, diet containing $40 \mathrm{~g}$ fructo-oligosaccharides $/ \mathrm{kg}$; TOS, diet containing $40 \mathrm{~g}$ galacto-oligosaccharides $/ \mathrm{kg}$.

* Mean values were significantly different from those for the control group, $P<0.05$.

$\uparrow$ For details of diets, see pp. 314-315.

Table 2. Composition of intestinal microflora ( $\log _{10}$ bacteria/g faeces) in gnotobiotic rats receiving diets containing different oligosaccharides $(40 \mathrm{~g} / \mathrm{kg}) \dagger$

(Mean values with their standard errors for six rats)

\begin{tabular}{|c|c|c|c|c|c|c|c|c|}
\hline & \multicolumn{2}{|c|}{ Control } & \multicolumn{2}{|c|}{ GOS } & \multicolumn{2}{|c|}{ FOS } & \multicolumn{2}{|c|}{ TOS } \\
\hline & Mean & SEM & Mean & SEM & Mean & SEM & Mean & SEM \\
\hline Total anaerobes & $10 \cdot 4$ & 0.05 & $10 \cdot 5$ & $0 \cdot 1$ & 10.4 & 0.1 & $10 \cdot 3$ & 0.2 \\
\hline Bacteroides & 9.6 & 0.1 & $9 \cdot 1$ & 0.3 & 9.2 & 0.2 & 9.0 & 0.1 \\
\hline Bifidobacterium & $7 \cdot 4$ & 0.4 & 7.0 & 0.2 & $9.2^{*}$ & 0.2 & $9 \cdot 6^{*}$ & 0.2 \\
\hline Clostridium & 7.7 & $0 \cdot 3$ & 7.0 & $0 \cdot 1$ & 7.0 & 0.2 & $7 \cdot 1$ & 0.3 \\
\hline Enterococcus & 7.9 & 0.2 & 7.4 & 0.4 & 7.6 & 0.2 & $7 \cdot 4$ & $0-6$ \\
\hline Enterobacteria & 6.8 & 0.1 & $6 \cdot 3$ & 0.3 & $6 \cdot 3$ & 0.2 & $6 \cdot 2$ & 0.6 \\
\hline
\end{tabular}

GOS, diet containing $40 \mathrm{~g}$ gluco-oligosaccharides $/ \mathrm{kg}$; FOS, diet containing $40 \mathrm{~g}$ fructo-oligosaccharides $/ \mathrm{kg}$; TOS, diet containing $40 \mathrm{~g}$ galacto-oligosaccharides $/ \mathrm{kg}$.

* Mean values were significantly different from those for the control group, $P<0.05$.

$\uparrow$ For details of diets, see pp. 314-315.

the other bacterial populations. FOS and TOS led to a significant increase up to 2 log of the Bifidobacterium faecal number.

\section{Bacterial glycolytic activities}

Compared with the control group, $\beta$-galactosidase (EC 3.2.1.23) activity was doubled in rats fed with the GOS diet (Table 3); $\alpha$ and $\beta$-glucosidases (EC 3.2.1.20/21) activities were significantly higher (1.7- and 3-fold) in rats fed on the diet containing $40 \mathrm{~g} \mathrm{GOS} / \mathrm{kg}$. In contrast, $\beta$-glucuronidase (EC 3.2.1.31) was reduced in the GOS group, whereas mucolytic activities remained unchanged. None of the glycolytic activities was modified by the FOS diet. TOS intake increased $\beta$-galactosidase activity strongly up to $8.1 \mathrm{IU} / \mathrm{g}$ without modification to the other activities studied.

\section{Gas production}

Compared with the control group, GOS intake reduced $\mathrm{H}_{2}$ production from 13 (SE 4) to 6 (SE 1) $\mu \mathrm{mol} / 10 \mathrm{~g}$ diet intake per $100 \mathrm{~g}$ body weight. FOS and TOS led to 3 - and 7 -fold increases respectively in $\mathrm{H}_{2}$ excretion (Fig. 1). 
Table 3. Bacterial glycolytic activities (IU/g of caecal contents) in rats receiving diets containing different oligosaccharides $(40 \mathrm{~g} / \mathrm{kg}) \dagger$

(Mean values with their standard errors for six rats)

\begin{tabular}{|c|c|c|c|c|c|c|c|c|}
\hline \multirow[b]{2}{*}{ Bacterial activities } & \multicolumn{2}{|c|}{ Control } & \multicolumn{2}{|c|}{ GOS } & \multicolumn{2}{|c|}{ FOS } & \multicolumn{2}{|c|}{ TOS } \\
\hline & Mean & SEM & Mean & SEM & Mean & SEM & Mean & SEM \\
\hline$\beta$-Galactosidase & 2.00 & 0.10 & $4 \cdot 00^{*}$ & 0.60 & 2.00 & 0.30 & $8 \cdot 10^{*}$ & 0.70 \\
\hline$\alpha$-Glucosidase & 0.87 & 0.03 & $1.52 *$ & 0.09 & 0.76 & 0.12 & 0.59 & 0.03 \\
\hline$\beta$-Glucosidase & $0 \cdot 16$ & 0.02 & $0 \cdot 50^{*}$ & 0.05 & 0.23 & 0.03 & 0.22 & 0.04 \\
\hline$\beta$-Glucuronidase & 0.25 & 0.06 & $0.13^{*}$ & 0.02 & 0.34 & 0.06 & $0 \cdot 19$ & 0.02 \\
\hline $\mathrm{N}$-acetylgalactosaminidase & 0.17 & 0.02 & 0.20 & 0.01 & 0.21 & 0.01 & 0.18 & 0.01 \\
\hline$\alpha$-L-Fucosidase & 0.06 & 0.01 & $0 \cdot 12$ & 0.02 & 0.07 & 0.01 & 0.07 & 0.01 \\
\hline
\end{tabular}

N-acetylgalactosaminidase, EC 3.2.1.49; $\alpha$-L-fucosidase, EC 3.2.1.51; GOS, diet containing 40 g gluco-oligosaccharides $/ \mathrm{kg}$; FOS, diet containing $40 \mathrm{~g}$ fructo-oligosaccharides $/ \mathrm{kg}$; TOS, diet containing $40 \mathrm{~g}$ galacto-oligosaccharides/ $\mathrm{kg}$.

* Mean values were significantly different from those for the control group, $P<0.05$

$\dagger$ For details of diets, see pp. 314-315.

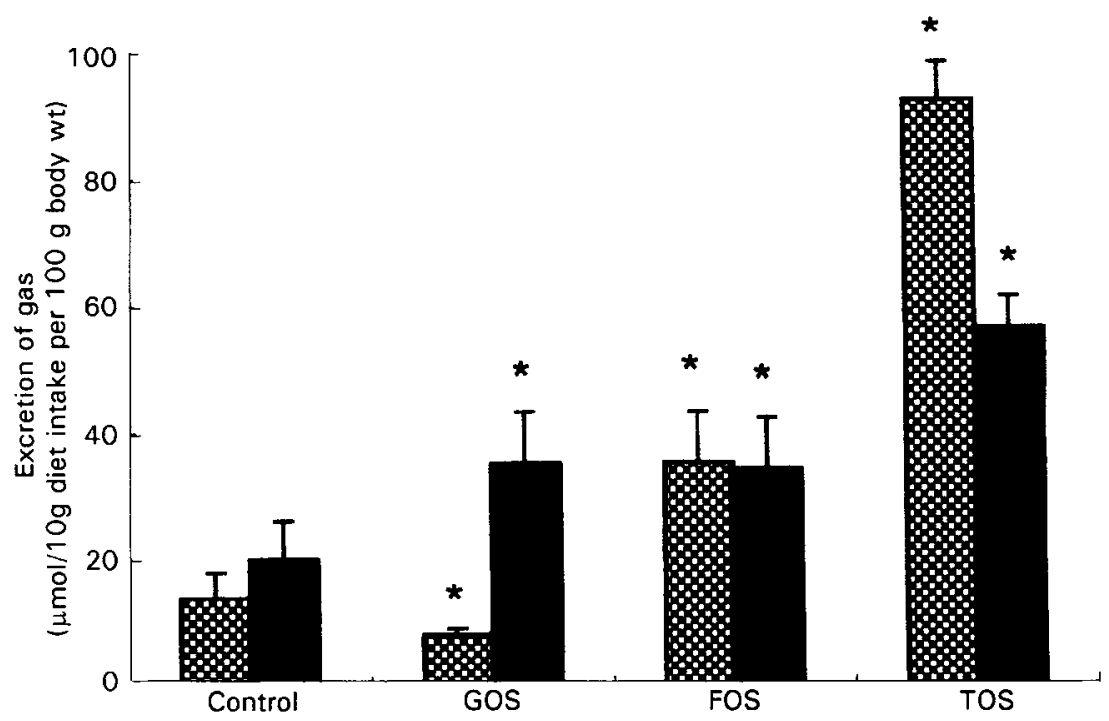

Fig. 1. Total excretion of hydrogen (10) and methane ( $\square$ ) by rats receiving diets containing $40 \mathrm{~g} / \mathrm{kg}$ of glucooligosaccharides (GOS), fructo-oligosaccharides (FOS) or galacto-oligosaccharides (TOS). Values are means with their standard errors represented by vertical bars for six rats. * Mean values were significantly different from those for the control group, $P<0.05$.

$\mathrm{CH}_{4}$ excretion increased 1.5-fold in the GOS and FOS groups (35 (SE 8) and 34 (SE 8) respectively), v. 21 (SE 5) $\mu \mathrm{mol} / 10 \mathrm{~g}$ diet intake per $100 \mathrm{~g}$ body weight in the control group. It was 2.5-fold higher in rats fed with the TOS diet than in the controls (54 (SE 5) $\mu \mathrm{mol} / 10 \mathrm{~g}$ diet per $100 \mathrm{~g}$ body weight).

\section{Fermentation in the caecum}

Caecal weight was increased by the GOS, FOS and TOS diets. The caecal pH was significantly and similarly reduced in the three groups compared with the control (Table 4). 
Table 4. Caecal weight, $p H$ and concentrations of short-chain fatty acids (SCFA), lactate and ammonia in the caecum of gnotobiotic rats receiving diets containing different oligosaccharides $(40 \mathrm{~g} / \mathrm{kg}) \dagger$

(Mean values with their standard errors for six rats)

\begin{tabular}{|c|c|c|c|c|c|c|c|c|}
\hline \multirow[b]{2}{*}{ Caecal variables } & \multicolumn{2}{|c|}{ Control } & \multicolumn{2}{|c|}{ GOS } & \multicolumn{2}{|c|}{ FOS } & \multicolumn{2}{|c|}{ TOS } \\
\hline & Mean & SEM & Mean & SEM & Mean & SEM & Mean & SEM \\
\hline Caecal weight & $5 \cdot 1$ & $0 \cdot 1$ & $7.4^{*}$ & 0.3 & $6 \cdot 3^{*}$ & 0.4 & $6 \cdot 6^{*}$ & 0.2 \\
\hline Caecal pH & $6 \cdot 4$ & 0.1 & $5 \cdot 9 *$ & 0.1 & $5.6 *$ & $0 \cdot 1$ & $5.8 *$ & 0.1 \\
\hline $\begin{array}{l}\text { Total SCFA } \\
(\mu \mathrm{mol} / \mathrm{g} \text { caecal contents })\end{array}$ & 31.5 & $2 \cdot 5$ & $60 \cdot 1 *$ & 1.6 & $56.5^{*}$ & 0.7 & $60 \cdot 0^{*}$ & $3 \cdot 2$ \\
\hline Acetate & 18.4 & 1.3 & $37.6 *$ & $1 \cdot 3$ & $36.4^{*}$ & $0 \cdot 3$ & $39 \cdot 0^{*}$ & 2.7 \\
\hline Propionate & 6.8 & 0.8 & $13 \cdot 8 *$ & 0.5 & $7 \cdot 4$ & 0.5 & $7 \cdot 7$ & 0.4 \\
\hline Butyrate & 4.7 & 0.5 & $6 \cdot 3$ & 0.4 & $11 \cdot 4^{*}$ & 0.6 & $10 \cdot 0^{*}$ & 0.5 \\
\hline Iso-acids & 1.6 & 1.0 & 2.4 & 0.3 & $1 \cdot 3$ & 0.1 & $3 \cdot 3 *$ & 0.6 \\
\hline $\begin{array}{l}\text { Ethanol } \\
\qquad(\mu \mathrm{mol} / \mathrm{g} \text { caecal contents })\end{array}$ & 1.5 & 0.1 & 1.5 & 0.1 & $3 \cdot 1^{*}$ & 0.5 & $3 \cdot 3 *$ & 0.5 \\
\hline $\begin{array}{l}\text { Lactate } \\
\qquad(\mathrm{mol} / \mathrm{g} \text { caecal contents })\end{array}$ & $5 \cdot 2$ & $0 \cdot 1$ & 5.7 & $0 \cdot 1$ & 5.9 & 0.2 & 5.0 & $0 \cdot 1$ \\
\hline L-Lactate $(\%)$ & 29 & & 26 & & 29 & & 30 & \\
\hline D-Lactate $(\%)$ & 71 & & 74 & & 71 & & 70 & \\
\hline $\begin{array}{l}\text { Ammonia } \\
(\mu \mathrm{mol} / \mathrm{g} \text { caecal contents })\end{array}$ & $5 \cdot 7$ & 0.1 & 4.9 & 0.3 & $3 \cdot 1^{*}$ & 0.2 & $2 \cdot 7^{*}$ & 0.2 \\
\hline
\end{tabular}

GOS, diet containing $40 \mathrm{~g}$ gluco-oligosaccharides $/ \mathrm{kg}$; FOS, diet containing $40 \mathrm{~g}$ fructo-oligosaccharides $/ \mathrm{kg}$; TOS, diet containing $40 \mathrm{~g}$ galacto-oligosaccharides $/ \mathrm{kg}$.

* Mean values were significantly different from those for the control group, $P<0.05$.

$\dagger$ For details of diets, see pp. 314-315.

Caecal SCFA concentration was almost doubled by the fermentation of the three oligosaccharides. Compared with the control group, the amount of acetate increased significantly in all groups. The amount of propionate increased only in rats fed on the GOS diet. Butyrate concentration was enhanced in rats fed with FOS and TOS. In rats fed on the TOS diet, the iso-acid concentration increased but the proportion of total SCFA remained the same (Table 4).

The SCFA pattern differed with the diet. Compared with the control, the proportion of acetate was enhanced with GOS $(63 \nu .58 \%)$, whereas the proportion of butyrate was lowered $(10 v .15 \%)$. The proportion of acetate was increased with both FOS and TOS (63 and $65 \%$ respectively $v .58 \%$ ). The butyrate proportion was also increased (20 and $17 \% v$. $15 \%$ ) whereas propionate was lowered from 22 to $13 \%$ (Fig. 2).

Ethanol concentration was doubled in the caecum of rats fed with FOS and TOS diets but was not modified with the GOS diet (Table 4). Lactate concentrations and the ratio L:D were similar in all groups.

Compared with the control group, $\mathrm{NH}_{3}$ concentration was similar in the GOS group, but was lowered in FOS and TOS groups (Table 4).

\section{DISCUSSION}

The three oligosaccharide diets led to similar increases in SCFA and to similar decreases in intestinal $\mathrm{pH}$ of the caecal contents of gnotobiotic rats, suggesting that the same amounts of GOS, FOS and TOS resisted endogenous digestion and reached the colon where they were fermented. In the present experiment, oligosaccharides had no effect on the total amount of bacteria as was observed previously in human subjects (Ito et al. 1993; Williams et al. 


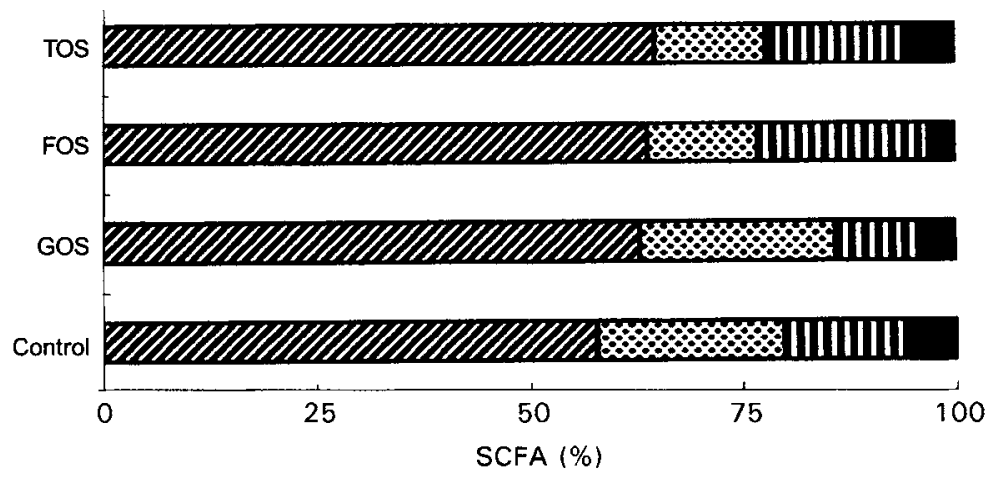

Fig. 2. Pattern of short-chain fatty acids (SCFA) in the caecal contents of gnotobiotic rats receiving diets containing $40 \mathrm{~g} / \mathrm{kg}$ of gluco-oligosaccharides (GOS), fructo-oligosaccharides (FOS) or galacto-oligosaccharides (TOS). (ZZ), Acetate; (\$D), propionate; (II)), butyrate; ( $\boldsymbol{D})$, isoacids. Values are means for six rats. The proportion of acetate was significantly enhanced with GOS; proportions of acetate and butyrate were significantly enhanced with FOS and TOS, $P<0.05$.

1994), although Rowland \& Tanaka (1993) observed a significant increase in total bacteria in rats colonized by a human faecal microflora. However, the effects of each carbohydrate on bacterial populations and bacterial metabolism differed widely.

TOS and FOS significantly increased the amount of Bifidobacterium in the faeces of gnotobiotic rats. This effect has previously been observed in human subjects (Tanaka et al. 1983; Mitsuoka et al. 1987; Matsumoto et al. 1989; Ito et al. 1990, 1993; Gibson et al. 1995) and in gnotobiotic rats (Rowland \& Tanaka, 1993). Since bifidobacteria are implicated in several potential health and nutritional benefits, i.e. anti-pathogenic and antidiarrhoeal, anti-tumoral and systemic effects (Mutai \& Tanaka, 1987; Mitsuoka, 1992), it is hypothesized that oligosaccharides which are able to induce Bifidobacterium growth would emphasize the properties attributed to these bacteria (Oku, 1994). Wang \& Gibson (1993) have recently demonstrated in vitro, that the growth of Bifidobacterium infantis has an inhibitory effect on the potentially pathogenic bacteria Esherichia coli and Clostridium perfringens when FOS is used as the carbohydrate source. Another potentially beneficial effect of both FOS and TOS with regard to bifidobacteria is related to the decrease of some bacterial activities including hydrolysis of glucuronides, reduction of nitrate and nitrocompounds, formation of $\mathrm{N}$ derivatives such as $\mathrm{NH}_{3}$, phenol, indole and skatol and conversion of food mutagens (Hidaka et al. 1986; Ito et al. 1993; Rowland \& Tanaka, 1993). However, in our present experiment, although FOS and TOS significantly modified the microflora composition, they had little effect on general glycolytic activities. TOS did not modify the $\beta$-glucosidase and $\beta$-glucuronidase activities, in contrast to earlier data from Kikuchi et al. (1992) and Rowland \& Tanaka (1993). Only the hydrolytic activities of the substrates were induced in rats: the $\beta$-galactosidase activity was enhanced by specific substrate induction by TOS. We did not measure fructohydrolase activity, but in human subjects Bouhnik et al. (1994) observed a significant increase of this activity when FOS was ingested.

GOS differed strongly from FOS and TOS since GOS did not change the major bacterial groups but modified numerous glycolytic activities. The increase of $\beta$ galactosidase and $\alpha$-glucosidase activities and the decrease of $\beta$-glucuronidase could be considered beneficial for the host. $\beta$-Galactosidase and $\alpha$-glucosidase activities can improve the fermentation of resistant starch and lactose leading to SCFA and lactic acids which are a source of energy for the tissues (Macfarlane \& Cummings, 1991) whereas $\beta$ - 
glucuronidase is involved in the generation of toxic and carcinogenic metabolites in the hindgut (Rowland, 1988). The increase in $\beta$-glucosidase activity is more ambiguous because this hydrolytic activity is responsible both for the generation of toxins (Mallet \& Rowland, 1988), and for the production of bacterial glucoside derivatives which are assumed to be responsible for protection against chemically induced cancer (Roland et al. 1993).

The mechanisms likely to explain the favourable effects of fermentable carbohydrates on bacterial activities are linked either to the change in pattern of the bacterial population, i.e. number of Bifidobacterium (Mutai \& Tanaka, 1987) or to modification of the intestinal medium, i.e. the intestinal $\mathrm{pH}$ (Mallet et al. 1989). The results obtained in the present study showed that neither the change of bacterial population nor the decrease of caecal $\mathrm{pH}$ are sufficient to explain the glycolytic activity variations. Glycolytic activities could be modified in a beneficial way without change in Bifidobacterium level, as shown with GOS; moreover, a similar decrease of $\mathrm{pH}$, observed with the three oligosaccharides, led to different changes in glycolytic activities depending on the oligosaccharide considered. We observed previously that gluco-oligosaccharides were more rapidly hydrolysed by Bacteroides than by Bifidobacterium species (Djouzi et al. 1995). Since Bacteroides were largely dominant in gnotobiotic rats in the present experiment with a faecal flora inoculum, this may explain why GOS had no apparent effect on the bacterial population.

With the exception of ethanol, the concentration of which increased in caecal contents of rats fed on FOS and TOS, the modifications induced by oligosaccharides in the profile of metabolites cannot be directly linked to the change in the bacterial population. The enhancement of Bifidobacterium induced by FOS and TOS did not lead to an increase in the proportions of acetate and L-lactate which are the metabolites produced by the glycolytic metabolism of the bifidobacteria. Fermentation of these oligosaccharides induced an increase in the butyrate concentration and in $\mathrm{H}_{2}$ production. This suggests that butyrate-producing bacteria were involved in the FOS and TOS metabolism; either because, like Bifidobacterium, they are able to hydrolyse these substrates, or because they utilized metabolites produced by the bifidobacteria. Thus, Clostridium, Eubacterium or Peptostreptococcus which are butyrate producers could participate in FOS and TOS hydrolysis in vivo as was observed in vitro (Matsumoto et al. 1989; Hidaka \& Hirayama, 1991). Some Clostridium species which are able to use lactate could be involved in these oligosaccharide fermentations. Similarly, in human subjects, Morishita et al. (1992) observed that when there is an increase in bifidobacteria there is also increased butyrate production. Indeed, since the latter is the most readily utilized energy source for the intestinal mucosa (Roediger, 1982) and appears to enhance proliferation of normal colonocytes and to inhibit the growth of a variety of cancer cell lines (Lupton, 1995), the increase in butyrate production would be beneficial for health. On the other hand, the associated gas production could lead to intestinal discomfort (Grimble, 1989). In humans, digestive problems and discomfort were observed with the ingestion of $16 \mathrm{~g}$ oligosaccharides/d (Ito et al. 1990; Drevon \& Bornet, 1992; Absolonne et al. 1995). Unlike FOS and TOS, GOS reduced $\mathrm{H}_{2}$ production and led to an increase in the proportion of propionate in the caecal contents. This increase in propionate production could be related to the ability of Bacteroides to hydrolyse GOS (Djouzi et al. 1995).

In contrast to the data of Tokunaga et al. (1986) in human subjects and those of Delzenne et al. (1993) in conventional rats, we did not observe a hypotriacylglycerolaemic effect of FOS in our gnotobiotic model. Delzenne et al. (1993) hypothesized that such changes are the consequence of a metabolic adaptation of the liver, because hepatocytes isolated from FOS-fed rats have a reduced capacity to synthesize triacylglycerols from free 
fatty acids and an increased capacity to catabolize fatty acids to ketone bodies. These authors pointed out differences in FOS influence depending on the amounts of FOS and fibre in the diet. The relatively low level of FOS along with differences in fibre and the nature and proportions of lipids added to our diet and the different strain of rats used could explain the discrepancy between experiments.

The three oligosaccharides significantly reduced plasma cholesterol concentrations. Similar effects were observed in both conventional rats and human subjects with FOS (Tokunaga et al. 1986; Hidaka \& Hirayama, 1991). Although it has been observed in vitro that propionate decreases cholesterol synthesis (Nishina \& Freedland, 1990) in gnotobiotic rats, the decrease in cholesterol level in the present study was probably not related to propionate production because only GOS modified both cholesterol level and propionate, whereas FOS and TOS, which also reduced the blood cholesterol level, did not lead to an increase in propionate production. In gnotobiotic rats given an increasing amount of TOS, we previously observed a correlated decrease between plasma cholesterol level and bacterial transformations of steroids, and an increase in bile acids originating from the biosynthetic pathway of chenodeoxycholate (Kikuchi et al. 1996). Moreover, in contrast with cholic acid, chenodeoxycholate and its derivatives did not promote cholesterol absorption (Uchida et al. 1980). This suggests that the hypocholesterolaemic effect of oligosaccharides could be linked more to hepatic cholesterol utilization than to cholesterol synthesis.

In conclusion, although the three oligosaccharides induced similar decreases in caecal $\mathrm{pH}$ and similar increases in SCFA caecal concentration, they had different effects on bacterial composition and bacterial metabolism, effects which could be beneficial to health. GOS improved the glycolytic activity and produced a low amount of gas; it could therefore improve the dietary digestibility and also alleviate the transitory deficiency of commensal bacteria as a consequence of certain antibiotic therapies. Although the induction of Bifidobacterium growth by FOS and TOS appears to be well established, the bacterial profile obtained with these two oligosacharides suggests that butyrate-producing bacteria are also involved in FOS and TOS fermentation. These bacteria should be identified. Anyway, such an increase of butyrate production may be beneficial for colonocyte metabolism. Indeed other experiments using microflora obtained from other human donors and experiments in human volunteers should be useful to confirm the specificity of GOS, FOS and TOS effects.

The authors wish to thank Bioeurope, Toulouse, France, the Raffinerie Tirlemontoise, Tienen, Belgium and the Yakult Institute, Tokyo, Japan, for the gift of oligosaccharides.

\section{REFERENCES}

Absolonne, J., Jossart, M., Coussement, P. \& Roberfoid, M. (1995). Digestive acceptability of oligofructose. First Orafti Research Conference, Proceedings, pp. 135-144. Tienen, Belgium: Orafti.

Andrieux, C., Lory, S., Dufour-Lescoat, C., de Baynast, R. \& Szylit, O. (1991). Physiological effects of inulin in germ-free rats and in heteroxenic rats inoculated with a human flora. Food Hydrocolloids 5, 49-56.

Beerens, H. (1990). An elective and selective isolation medium for Bifidobacterium spp. Letters in Applied Microbiology 11, 155-157.

Bergman, E. N. (1990). Energy contributions of volatile fatty acids from the gastrointestinal tract in various species. Physiological Reviews 70, 567-590.

Bond, J. H., Engel, R. R. \& Levitt, M. D. (1971). Factors influencing pulmonary methane excretion in man. Journal of Experimental Medicine 133, 572-588.

Bouhnik, Y., Flourié, B., Ouarné, F., Bisetti, N., Bornet, F. \& Rambaud, J. C. (1994). Effets de l'administration prolongée de fructo-oligosaccharides (Actilight ${ }^{\circledR}$ ) sur la flore bactérienne colique de l'homme (Effects of 
chronic fructo-oligosaccharides (Actilight ${ }^{(\mathbb{R})}$ ) ingestion on the human colonic microflora). Gastroentérologie Clinique et Biologique 18, 50A.

Debure, A., Colombel, J. F., Flourié, B., Rautureau, M. \& Rambaud, J. C. (1989). Comparaison de l'implantation et de l'activité métabolique d'une flore fécale de rat et d'une flore fécale humaine inoculées chez le rat axénique (Implantation and metabolic activity of rat and human faecal bacterial flora administered to germ-free rats). Gastroentérologie Clinique et Biologique 13, 25-31.

Delzenne, N., Kok, N., Fiordalso, M. F., Deboyser, D., Goethals, F. \& Roberfroid, M. (1993). Dietary fructooligosaccharides modify lipid metabolism in the rat. American Journal of Clinical Nutrition 57, Suppl. 820.

De Simone, C., Vesely, R., Bianchi Salvadori, B. \& Jirillo, E. (1993). Influence of long term yoghurt consumption in young adults. International Journal of Immunotherapy 7, 205-210.

Djouzi, Z., Andrieux, C., Pelenc, V., Somarriba, S., Popot, F., Paul, F., Monsan, P. \& Szylit, O. (1995). Degradation and fermentation of $\alpha$-gluco-oligosaccharides by bacterial strains from human colon: in vitro and in vivo studies in gnotobiotic rats. Joumal of Applied Bacteriology 79, 117-127.

Drevon, T. \& Bornet, F. (1992). Les fructo-oligosaccharides, Actilight ${ }^{\circledR}$ (Fructo-oligosaccharides, Actilight ${ }^{\circledR}$ ). In Sucre, Produits Sucrants, Edulcorants et Substances Glucidiques de Charge dans les Industries Alimentaires. Techniques et Documentation. Collection Sciences et Techniques Agro-Alimentaires. pp. 314 337 [J. L. Multon, editor]. Paris: Lavoisier et Apria.

Dropsy, G. \& Boy, J. (1965). Détermination de l'ammoniémie (méthode automatique par dialyse) (Ammonia determination in urine). Annales de Biologie Clinique 19, 313-318.

Fernandes, C. F. \& Shahani, K. M. (1990). Anticarcinogenic and immunological properties of dietary lactobacilli. Journal of Food Protection 53, 704-710.

Gibson, G. R., Beatty, E. R., Wang, X. \& Cummings, J. H. (1995). Selective stimulation of bifidobacteria in the human colon by oligofructose and inulin. Gastroenterology 108, 975-982.

Gilliland, S. E. (1990). Health and nutritional benefits from lactic acid bacteria. FEMS Microbiology Reviews 87, $175-188$.

Goldin, B. R. \& Gorbach, S. L. (1984). The effect of milk and Lactobacillus feeding on human intestinal bacterial enzyme activity. American Journal of Clinical Nutrition 39, 756-761.

Grimble, G. (1989). Fibre, fermentation, flora and flatus. Gut 30, 6-13.

Hidaka, H., Eida, T., Takizawa, T., Tokunga, T. \& Tashiro, Y. (1986). Effects of fructooligosaccharides on intestinal flora and human health. Bifidobacteria Microflora 5, 37-50.

Hidaka, H. \& Hirayama, M. (1991). Useful characteristics and commercial applications of fructooligosaccharides. Biochemical Society Transactions 19, 561-565.

Hitchins, A. D. \& McDonough, F. E. (1989). Prophylactic and therapeutic aspects of fermented milk. American Journal of Clinical Nutrition 49, 675-684.

Ito, M., Deguchi, Y., Matsumoto, K., Kimura, M., Onodera, N. \& Yajima, T. (1993). Influence of galactooligosaccharides on the human faecal microflora. Journal of Nutritional Science and Vitaminology 39, 635-640.

Ito, M., Deguchi, Y., Miyamori, A., Matsumoto, K., Kikuchi, H., Matsumoto, K., Kobayashi, Y., Yajima, T. \& Kan, T. (1990). Effects of administration of galactooligosaccharides on the human faecal microflora, stool weight and abdominal sensation. Microbial Ecology in Health and Disease 3, 285-292.

Kikuchi, H., Andrieux, C., Riottot, M., Bensaada, M., Popot, F., Beaumatin, P. \& Szylit, O. (1996). Effect of two levels of transgalactosylated oligosaccharide intake in rats associated with human faecal microflora on bacterial glycolytic activity, end-products of fermentation and bacterial steroid transformation. Journal of Applied Bacteriology 80, 439-446.

Kikuchi, H., Andrieux, C. \& Szylit, O. (1992). Effects of galacto-oligosacharides on bacterial enzymic activities and metabolite production in rats associated with a human flora. Proceedings of the Nutrition Society 51, 7A.

Le Coz, Y., Morel, M. T., Bousseboua, H., Dufour, C. \& Szylit, O. (1989). Mise au point d'une chambre respiratoire connectée sur l'isolateur pour la mesure in vivo des gaz de fermentation chez l'animal gnotoxénique (Respiratory chamber associated to isolator for measuring the in vivo production of gas in the gnotobiotic animal). Science et Technologie des Animaux de Laboratoire 14, 35-39.

Lupton, J. R. (1995). Short-chain fatty acids and colon tumorigenesis: animal models. In Physiological and Clinical Aspects of Short-Chain Fatty Acids, pp. 308-318 [J. H. Cummings, J. L. Rombeau and T. Sakata, editors]. Cambridge: Cambridge University Press.

Macfarlane, G. T. \& Cummings, J. H. (1991). The colonic flora, fermentation and large bowel digestive function. In The Large Intestine: Physiology, Pathophysiology and Disease, pp. 51-92 [S. F. Phillips, J. H. Pemberton and R. G. Shorter, editors]. New York: Raven Press.

Mallett, A. K., Beame, C. A. \& Rowland, I. R. (1989). The influence of incubation pH on the activity of rat and human gut flora enzymes. Journal of Applied Bacteriology 66, 433-437.

Mallett, A. K., Bearne, C. A., Rowland, I. R., Farthing, M. G. J., Cole, C. B. \& Fuller, R. (1987). The use of rats associated with a human faecal flora as a model for studying the effects of diet on the human gut microflora. Journal of Applied Bacteriology 63, 39-45. 
Mallet, A. K. \& Rowland, I. R. (1988). Factors affecting the gut microflora. In Role of the Gut Flora in Toxicity and Cancer, pp. 347-382. London: Academic Press.

Marteau, P., Pochart, P., Flourié, B., Pellier, P., Santos, L., Desjeux, J. F. \& Rambaud, J. C. (1990). Effect of chronic ingestion of fermented dairy product containing Lactobacillus acidophilus and Bifidobacterium bifidum on metabolic activities of the colonic flora in humans. American Journal of Clinical Nutrition $\mathbf{5 2}$, 685-688.

Matsumoto, K., Kobayashi, Y., Tamura, N., Watanabe, T. \& Kan, T. (1989). Production of galactooligosaccharides with $\beta$-galactosidase. Denpun Kagaku 36, 123-130.

Mitsuoka, T. (1982). Recent trends in research on intestinal flora. Bifidobacteria Microflora 1, 3-24.

Mitsuoka, T. (1992). The human gastrointestinal tract. In The Lactic Acid Bacteria in Health and Disease, vol. 1, pp. 69-114 [B. J. B. Woods, editor]. London and New York: Elsevier Applied Science.

Mitsuoka, T., Hidaka, H. \& Eida, T. (1987). Effect of fructo-oligosaccharides on intestinal microflora. Die Nahrung 31, 427-436.

Morishita, Y., Knishi, Y., Tanaka, R. \& Mutai, M. (1992). The effect of transgalactosylated oligosaccharide (TOS) on the intestinal microflora and the heat resistance of fecal bacteria in rats. Bifidus 6, 11-17.

Mutai, M. \& Tanaka, R. (1987). Ecology of Bifidobacterium in the human intestinal flora. Bifidobacteria Microflora 6, 33-41.

Nishina, P. M. \& Freedland, R. A. (1990). Effects of propionate on lipid biosynthesis in isolated rat hepatocytes. Journal of Nutrition 120, 668-675.

Oku, T. (1994). Special physiological functions of newly developed mono- and oligosaccharides. In Functional Foods Designer Foods, Pharmafoods, Nutraceuticals, pp. 202-218 [I. Goldberg, editor]. New York: Chapman \& Hall.

Roediger, W. E. W. (1980). Role of anaerobic bacteria in the metabolic welfare of the colonic mucosa. Gut 21, 793-798.

Roediger, W. E. W. (1982). Utilization of nutrients by isolated epithelial cells of rat colon. Gastroenterology 83, $424-429$.

Roland, N., Nugon-Baudon, L. \& Rabot, S. (1993). Interactions between the intestinal flora and xenobiotic metabolizing enzymes and their health consequences. World Review of Nutrition and Dietetics 74, 123-148.

Rowland, I. R. (1988). Factors affecting metabolic activity of the intestinal microflora. Drug Metabolism Reviews 19, 243-261.

Rowland, I. R. \& Tanaka, R. (1993). The effects of transgalactosylated oligosaccharides on gut flora metabolism in rats associated with human faecal microflora. Journal of Applied Bacteriology 74, 667-674.

Rumney, C. J. \& Rowland, I. R. (1992). In vivo and in vitro models of the human colonic flora. Critical Reviews in Food Science and Nutrition 31, 299-331.

Saavedra, J. M., Bauman, N. A., Oung, I., Perman, J. A. \& Yolken, R. H. (1994). Feeding of Bifidobacterium bifudum and Streptococcus thermophilus to infants in hospital for prevention of diarrhoea and shedding of rotavirus. Lancet 344, 1046-1049.

Schriffrin, E. J., Rochat, F., Link-Amster, H., Aeschlimann, J. M. \& Donnet-Hugues, A. (1995). Immunomodulation of human blood cells following the ingestion of lactic acid bacteria. Journal of Dairy Science 78, 491-497.

Segal, I., Walker, A. R. P., Lord, S. \& Cummings, J. H. (1988). Breath methane and large bowel cancer risk in contrasting African populations. Gut 29, 608-613.

Tamura, Z. (1983). Nutriology of Bifidobacteria. Bifidobacteria Microflora 2, 3-16.

Tanaka, R., Takayama, H., Morotomi, M., Kuroshima, T., Ueyama, S., Matsumoto, K., Kuroda, A. \& Mutai, M. (1983). Effects of administration of TOS and Bifidobacterium breve 4006 on the human faecal flora. Bifidobacteria Microflora 2, 17-24.

Tokunaga, T., Oku, T. \& Hosoya, N. (1986). Influence of chronic intake of new sweetener fructooligosaccharide (Neosugar) on growth and gastrointestinal function of the rat. Journal of Nutritional Science and Vitaminology 32, 111-121.

Trexler, P. C. (1959). The use of plastics in the design of isolator systems. Annals of the New York Academy of Sciences 78, 29-36.

Uchida, K., Nomura, Y. \& Takeuchi, N. (1980). Effect of cholic acid, chenodeoxycholic acid, and their related bile acids on cholesterol, phospholipid, and bile acids levels in serum, liver, bile, and faeces of rats. Journal of Biochemistry 87, 187-194.

Valette, P., Pelenc, V., Djouzi, Z., Andrieux, C., Paul, F., Monsan, P. \& Szylit, O. (1993). Bioavailability of new synthesised glucooligosaccharides in the intestinal tract of gnotobiotic rats. Journal of the Science of Food and Agriculture 62, 121-127.

Wang, X. \& Gibson, G. R. (1993). Effects of the in vitro fermentation of oligofructose and inulin by bacteria growing in the human large intestine. Journal of Applied Bacteriology 75, 373-380.

Williams, C. H., Witherly, S. A. \& Buddington, R. K. (1994). Influence of dietary neosugar on selected bacterial groups of the human faecal microbiota. Microbial Ecology in Health and Disease 7, 91-97. 